\title{
Correspondence
}

\section{Anaesthesia simulators (1)}

To the Editor:

We read the editorial entitled "The Virtual Anesthesiology(ii) Training Simulation System" with interest. ${ }^{1}$ We acquired such a device in January 1995 and would like to offer some additional observations.

The training device described in the editorial is one of two such devices commercially available in North America. Each has its own particular advantages and disadvantages. Those intending to purchase anaesthesia simulation systems would be advised to review carefully both products in order to determine which best suits individual educational requirements.

Among the various applications of simulator-based education in health care, the most developed educational role for anaesthesia simulators is the Anaesthesia Crises Resource Management (ACRM) Workshop. ${ }^{2}$ ACRM is a concept derived from training cockpit crews and adapted to anaesthesia by Dr. Gaba and his group at the Veteran Administration Hospital in Palo Alto. Those concepts were incorporated into a one-day course for up to six clinicians at the Boston Simulation Centre at Harvard Medical School by Dr. Cooper and his group. The goals of the ACRM workshop are to develop decisionmaking, communication, leadership and stress management skills. Several hundred anaesthetists in North America have completed workshops offered at Stanford University, Harvard School of Medicine and Sunnybrook Health Science Centre, University of Toronto.

To achieve the realism demanded by these courses a simulation device is only the beginning of what is needed. Other items required include an "operating room," anaesthetic machine, patient monitors, drug cart, operating room table, intravenous stand, extensive audiovisual equipment and personnel for role playing. In our experience the capital costs are just the beginning. Maintenance, operating and upgrade costs as well as stipends for instructors requires ongoing funding. These additional costs will likely exceed the initial capital outlay.

Having had the experience of setting up a medical simulation facility we are willing to offer our knowledge and experience to other centers wishing to acquire such a device or train instructors in ACRM.

J.H. Devitt MD MSc FRCPC

M. Kurrek MD FRCPC

Sunnybrook Health Science Centre

\author{
University of Toronto \\ K.J. Fish MB ChB FRCPC \\ VA Medical Center \\ Palo Alto \\ Stanford University
}

\section{REFERENCES}

1 Doyle DJ, Arellano R. The Virtual Anesthesiology (i)

Training Simulation System (Editorial). Can J Anaesth 1995; 42: 267-73.

2 Howard SK, Gaba DM, Fish KJ, Yang G, Sarnquist FH. Anesthesia crisis resource management training: teaching anesthesiologists to handle critical incidents. Aviat Space Environ Med 1992; 63: 763-70.

\section{$R E P L Y(1)$ \\ Dr. Devitt is to be commended for his department's efforts in setting up a Canadian Anaesthesia Simulator Program at the Sunnybrook Health Science Centre. I have no doubt that his efforts and those of his colleagues will ultimately improve the quality of anaesthesia services in Canada, as well as provide new research results in the area of crisis management in the operating room.}

D. John Doyle MD PhD FRCPC

Department of Anaesthesia

The Toronto Hospital

\section{Anaesthesia simulators (2)}

To the Editor:

I wish to clarify certain issues discussed in the editorial by Doyle and Arellano (Doyle DJ, Arellano R. The Virtual Anesthesiology (10) Training Simulation System. Can J Anaesth 1995, 42: 267-73). In this editorial the authors state: "We acquired a prototype form of simulation technology from Dr. Gaba and Dr. Williams of Stanford University, with contributions (mostly pharmacokinetic and pharmacodynamic models) from Dr. Schwid of the University of Washington." To the best of my knowledge we have never sent the authors any prototype simulator technology. As they state, however, they were able to evaluate the CAE-Link simulator device at the factory in Binghamton, New York. This system is based in part on technologies licensed to CAE-Link by the aforementioned Drs. Gaba, Williams, and Schwid, as well as CAE-Link proprietary technologies. I am honoured 
by the authors' positive evaluation of this simulator system.

Two other items should be called to the attention of the reader. First, I find it puzzling that the authors did not mention that a simulation centre using a simulator from CAE-Link (the company is now known as CAE Electronics Incorporated) had been under design and construction at Sunnybrook Health Science Centre/University of Toronto since the summer of 1994. This facility opened several months ago and is currently engaged in a variety of training and research activities using the simulator, including the intensive training course in Anaesthesia Crisis Resource Management. Second, in their discussion of the use of simulation for training in anesthetic crises I believe that mention should be made of the special simulator-based curriculum on Anesthesia Crisis Resource Management $(A C R M)^{1-3}$ that was pioneered by my laboratory in 1990 , and that is currently being offered at three simulator centers affiliated with major teaching institutions 1,24,5 in North America (Stanford University, Harvard University, University of Toronto).

David M. Gaba MD

Stanford University School of Medicine

Palo Alto Veterans Affairs Medical Center

\section{REFERENCES}

1 Howard SK, Gaba DM, Fish KJ, Yang GS, Sarnquist FH. Anesthesia crisis resource management training: teaching anesthesiologists to handle critical incidents. Aviat Space Environ Med 1992; 63: 763-70.

2 Holzman RS, Cooper JB, Gaba DM, Philip JH, Small S, Feinstein D. Participant responses to realistic simulation training in anesthesia crisis resource management (ACRM) Anesthesiology 1993; 79: Al112.

3 Gaba DM, Botney R, Howard SK, Fish KJ, Flanagan $B$. Interrater reliability of performance assessment tools for the management of simulated anesthetic crises. Anesthesiology 1994; 81: A1277.

4 Holzman RS, Cooper JB, Gaba DM, Philip JH, Small S, Feinstein $D$. Anesthesia crisis resource management: reallife simulation training in operating room crises. $J$ Clin Anesth (in press).

5 Kurrek MM, Small S, Feinstein D, Russell R, Fish K, Gaba $D$ Anaesthesia Crisis Resource Management (ACRM) instructor course - teaching the teachers (abstract). Presented at the Conference on Simulators in Anesthesia Education, Rochester, NY, 1995.

\section{$R E P L Y(2)$}

$A$ check of our final submitted manuscript revealed that we had originally written "The simulation technology used in the system was acquired in prototype form from Dr. Gaba and
Dr. Williams of Stanford University, with contributions (mostly pharmacokinetic and pharmacodynamic models) from Dr. Schwid of the University of Washington." The change to "We acquired a prototype ..." was later made at the CJA editorial office and unfortunately escaped our notice. As stated, our assessment was based on using the unit on a trip to the $C A E$ factory in Binghamton, New York.

Dr. Gaba was puzzled by our failure to mention the simulator at the Sunnybrook Health Science Centre. However, at the time our original manuscript was submitted, Sunnybrook had not even been chosen as a simulator site. Indeed, the main purpose of our assessment of the CAE system was to explore the possibility of acquiring it for the Toronto Hospital. We are, however, very pleased that Sunnybrook has since taken on a strong leadership role in providing anaesthesia simulator services to Canadians.

Finally, we regret that tight space limitations did not allow us to cite the abstracts on Anaesthesia Crisis Resource Management to which Dr. Gaba refers. We are sure that when they are eventually published as full papers, they will be valuable contributions to the anaesthesia literature.

\section{John Doyle MD PhD FRCPC}

Ramiro Arellano MD FRCPC

Department of Anaesthesia

The Toronto Hospital

\section{Respiratory depression associated with patient- controlled analgesia}

To the Editor:

Respiratory depression associated with patient-controlled analgesia (PCA) was recently reviewed ${ }^{1}$ with an accompanying editorial. ${ }^{2}$ Risk factors included concurrent use of background infusions, advanced age, concomitant administration of sedative/hypnotic medications, preexisting sleep apnoea syndrome, and excessively liberal prescribing. We report a patient who suffered severe respiratory depression when epidural analgesia was changed to $\dot{N}$ PCA.

The patient, a 44-yr-old, ASA 2, $74 \mathrm{~kg}$ man underwent partial gastrectomy for gastric carcinoma. Before general anaesthesia, an epidural catheter was inserted at $T_{9-10}$. Intraoperative analgesia was provided with epidural bupivacaine (76.25 mg) and epidural fentanyl $(150 \mu \mathrm{g})$. Postoperative analgesia was with a continuous epidural infusion of bupivacaine $0.1 \%$ with meperidine $2 \mathrm{mg}^{\prime} \mathrm{ml}^{-1}$ adjusted, after initial titration, to $7.5 \mathrm{ml} \cdot \mathrm{hr}^{-1}$. After surgery, he was pain-free and satisfied. The following morning, whilst comfortable, the epidural catheter was removed for technical reasons. Further analgesia was with iv morphine by PCA (bolus $2 \mathrm{mg}$, lockout $5 \mathrm{~min}$, fourhour maximum $30 \mathrm{mg}$ ) and no background infusion. Seven hours later, the patient was found unresponsive 